\title{
GSK-3 protein and the heart: friend or foe?
}

\section{B. Huisamen and A. Lochner}

MRC Cape Heart Centre, Department of Biomedical Sciences,

Division Medical Physiology, Faculty of Health Sciences,

University of Stellenbosch, Tygerberg

Address for correspondence:

Prof Barbara Huisamen

Department of Biomedical Sciences

Division Medical Physiology

Faculty of Health Sciences

University of Stellenbosch

PO Box 19063

Tygerberg

Parow

7505

South Africa

Email:

bh3@sun.ac.za

\section{GSK-3 INHIBITION AS FUTURE DRUG TARGET}

Glycogen synthase kinase-3 (GSK-3) was identified in the early 1980 s as an enzyme involved in the control of glycogen metabolism, and extensively researched, especially in the context of the metabolic actions of insulin.(I) Currently, interest in this kinase has flared because of the development of new generations of inhibitors with specific clinical implications, especially in the potential of these inhibitors to treat diseases that currently have significant limitations in therapeutic treatments, e.g. type 2 diabetes, Alzheimer's disease, stroke and bipolar- and mood disorders. ${ }^{(2)}$ The prototype of a GSK-3 inhibitor is lithium, although the mechanism of this inhibition is not understood. ${ }^{(69)}$ There is no clinical data available at present on the inhibition of GSK-3, but preclinical data supports an important future role. Scant preclinical data is available in the field of heart research, but, as this review has tried to summarise, the available evidence, as well as the multiplicity of actions of this kinase,

\section{ABSTRACT}

Metabolic syndrome manifesting as obesity, insulin resistance and type 2 diabetes mellitus is currently pandemic. Each of these, in its own right, is strongly related to the development of cardiovascular disease. The cardiomyopathy associated with these disorders is characterised by curtailed glucose uptake and utilisation, elevated risk of damage after ischaemia and contractile dysfunction. Current research have indicated that the serine/threonine kinase, glycogen synthase kinase 3 (GSK-3), may play a central role in the development of all these dysfunctions. The development of new generations of inhibitors of this kinase, has renewed interest in its utilisation as therapeutic target. This review has therefore focused on the role of GSK-3 in the development of the obesity-related cardiomyopathy and has highlighted and discussed the detrimental as well as beneficial effects of the GSK-3 inhibitors that are currently available. We have discussed the different roleplayers such as the insulin signalling pathway, modulation of apoptosis and mitochondrial function, SERCA2 expression and regulation of the development of hypertrophy in the context of GSK-3 activity. SAHeart 2010; 7:48-57

argue strongly that its inhibition may also become an important future drug target in this field.

\section{A CENTRAL ROLE FOR GSK-3 IN INSULIN} SIGNALLING

Whole-body glucose homeostasis is a continuous process and a function of the production of glucose by the liver and the peripheral disposal of glucose, primarily by skeletal muscle. These two processes are regulated by several endocrine factors, the most important of which are insulin and glucagon, produced by the pancreatic $\beta$ - and $\alpha$-cells respectively.

Hepatic glucose production is mediated by both glycogenolysis and gluconeogenesis. When there is increased glucose demand by peripheral tissue, e.g. muscle contraction during exercise, the liver must produce glucose accordingly to prevent development of 
hypoglycemia. These processes are governed by a decrease in insulin secretion and an increase in glucagon secretion, as well as by changes in adrenalin and cortisol secretion.

As a continuously contracting muscle, the heart uses between 3.5 and $5 \mathrm{~kg}$ of ATP per day. To produce this, glucose, fatty acids, amino acids and ketones are readily used as fuel substrates ${ }^{(3)}$. Muscle glucose utilisation is acutely regulated by insulin (Figure I). This is accomplished through a series of events initiated by binding of insulin to the $\alpha$-subunit of the insulin receptor, leading to autophosphorylation of the membrane-spanning $\beta$-subunit. The activated insulin receptor, a proto-type tyrosine kinase enzyme, leads to the sequential activation of a kinase cascade involving insulin receptor subtstrate proteins (IRSs), Pl-3-Kinase (phosphatidylinositol-3-kinase) and protein kinase B/Akt. Activation of PKB/Akt is a prerequisite for the translocation of the insulin regulated glucose transporter, glut 4, from intracellular storage vesicles to the cell membrane to facilitate glucose uptake. ${ }^{(4)}$ Glut 4 is the major transporter responsible for uptake of glucose into heart muscle after stimulation with insulin or after anoxia or ischaemia of the muscle. Glut I, previously taken to be responsible for basal glucose uptake, is apparently more concentrated in the endothelial cells of the microvasculature of the heart and does not respond to insulin with translocation from one compartment to another. ${ }^{(5)}$

On cell entry, glucose can either be shunted into glycolytic pathways and metabolised to pyruvate or converted to glycogen via activation of the enzyme glycogen synthase (GS). Stimulation of muscle cells with insulin activates pathways that enhance glycogen formation. PKB/Akt was initially described as the kinase leading to activation of GS after insulin stimulation via phosphorylation of glycogen synthase kinase-3. ${ }^{(6)}$

The mammalian heart expresses 2 isoforms of glycogen synthase kinase-3 (GSK-3). GSK-3 $\alpha$ and GSK-3 $\beta$ exhibit a high degree of sequence similarity and have molecular masses of 51 and $47 \mathrm{kDa}$

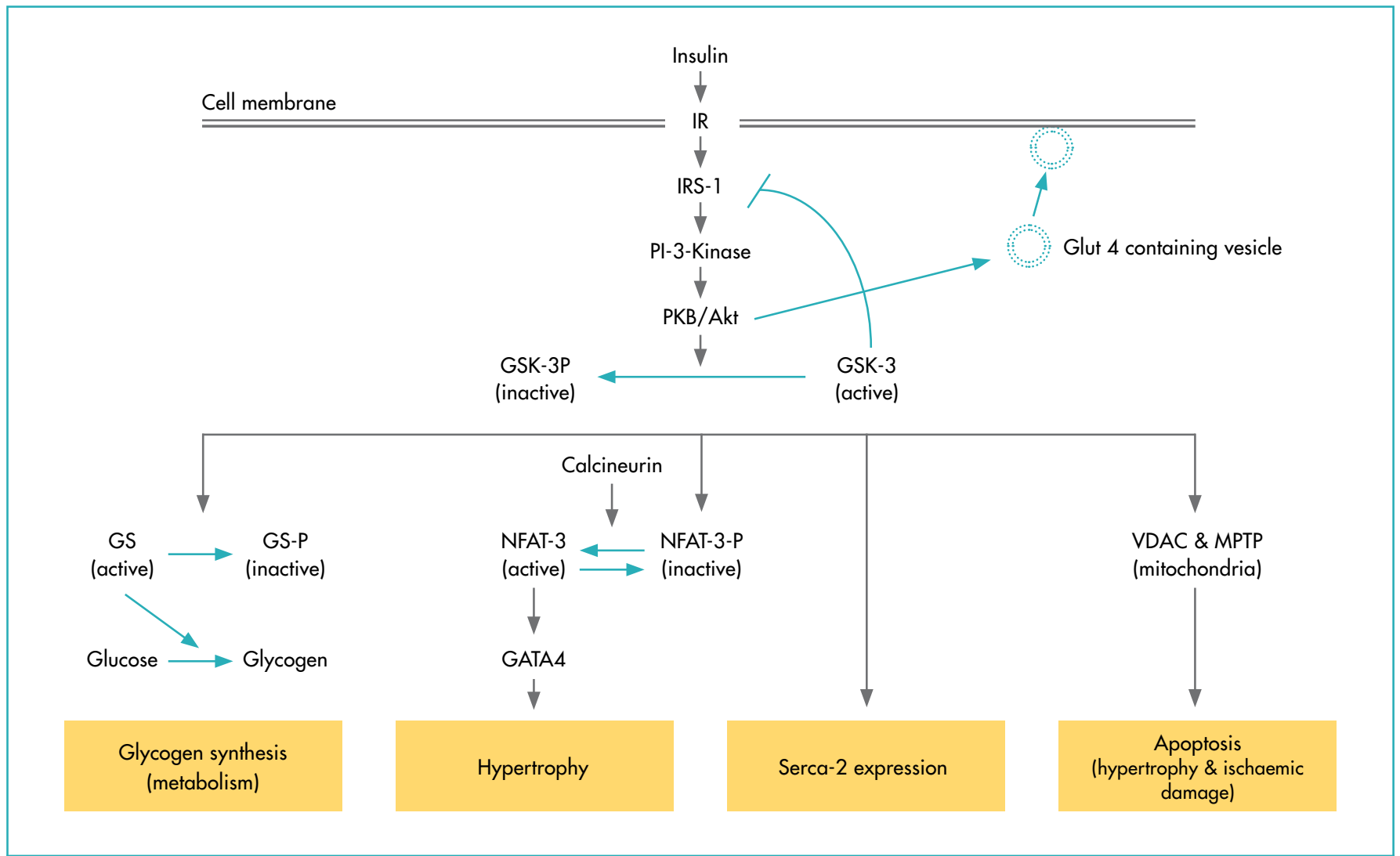

FIGURE I: A general schematic representation of the signal transduction pathways involved in GSK-3 activity.

IR: insulin receptor, IRS-I: insulin receptor substrate-I, PI-3-Kinase: phosphatidyl inositol-3-kinase, PKB/Akt: protein kinase B, GSK-3: glycogen synthase kinase-3, GS: glycogen synthase, NFAT: nuclear factor of activated T-cell, GATA4: Zink finger transcription factor, VDAC: voltage dependent anion channel, MPTM: mitochondrial permeability transition pore. 
respectively. PKB/Akt phosphorylates both isoforms of GSK-3 on Ser2I and Ser9 respectively. GSK-3 is constitutively active in resting cells and its activity is negatively regulated by this phosphorylation. ${ }^{(7)}$ As reviewed by Sugden et al., ${ }^{(8)}$ this negative regulation can also be accomplished by other kinases such as ribosomal S6 kinase, (S6K), p90-ribosomal S6 kinase (RSK), the mitogen and stress activated protein kinases (MSK's), serum and glucocorticoidregulated kinase (SGK's) as well as CAMP-dependent protein kinase, PKA. All of these signalling pathways are highly relevant in cardiovascular physiology and pathophysiology. In vivo, inhibition of GSK-3 and activation of GS by insulin, is mainly regulated by the pathway involving PI-3-Kinase and PKB/Akt. ${ }^{(9)}$ Besides glycogen synthesis, the expression and activation of GSK-3 protein impacts on diverse cellular processes such as glucose transport, gene transcription, cell differentiation, cell survival or -death (apoptosis), as well as muscle contractility. ${ }^{(10)}$

\section{INSULIN RESISTANCE}

The pre-dominant role of insulin is the maintenance of whole body glucose homeostasis. Although this has been known for many years, it was not until 1949 that the ability of insulin to stimulate glucose uptake was experimentally demonstrated.( ${ }^{(1)}$ PKB/Akt, as mediator of the metabolic effects of insulin, promotes glucose uptake in vascular-, skeletal muscle and adipose tissue. ${ }^{(12)}$ It is well-established that insulin stimulates glucose uptake also in heart muscle. Using 2-deoxy-D- ${ }^{3}[\mathrm{H}]$ - glucose (2DG) uptake in primary neonatal ${ }^{(13)}$ or adult ${ }^{(14)}$ rat cardiomyocytes as a readout of insulin response, it was demonstrated that insulin stimulation leads to increased 2DG uptake. Cardiac glucose uptake is dependent on the transmembrane glucose gradient as well the content of sarcolemmal glucose transporters, glut I and glut $4,{ }^{(15,16)}$ with glut 4 considered to be the principal contributor to the regulation of glucose uptake by insulin. ${ }^{(17)}$ Insulin via PKB/Akt activation induces the translocation of glut 4 from the intracellular storage vesicles to the sarcolemmal membrane to facilitate glucose entry. ${ }^{(17,18)}$

Metabolic syndrome is a cluster of metabolic disturbances that together define a progressive condition associated with development of type 2 diabetes mellitus and cardiovascular disease. ${ }^{(19-21)}$
It is estimated that metabolic syndrome affects approximately one quarter of the population in developed countries. ${ }^{(22)}$ The National Cholesterol Education Programme's Adult Treatment Panel III (NCEP: ATP III) and the European Group for the Study of Insulin Resistance, identified central-abdominal obesity, atherogenic dyslipidaemia (hypertriglyceridaemia and reduced high-density lipoprotein-cholesterol), raised blood pressure, insulin resistance and glucose intolerance as components for metabolic syndrome. ${ }^{(23,24)}$ Furthermore, it has been reported that each component of the syndrome may be considered as independent risk factors for cardiovascular disease. ${ }^{(24)}$ Over the past two decades, the number of people with metabolic syndrome has increased at an alarming rate. This increase is associated with the global epidemic of both obesity and diabetes. ${ }^{(25)}$

The inability of cells to respond appropriately to a certain level of insulin, is termed insulin resistance. ${ }^{(26)}$ This is a defect associated with a variety of disorders including metabolic syndrome, atherosclerosis, hypertension, dyslipidaemia, type 2 diabetes and heart failure. Increased cardiovascular risk is central to all these disorders and has been ascribed by some to the elevated plasma insulin levels that accompany insulin resistance. (27) However, the United Kingdom Prospective Diabetes Study could not detect a correlation between higher cardiovascular risk and elevated insulin levels. ${ }^{(28)}$ Alternatively, obesity, with the accompanying elevated plasma free fatty acid levels, has been identified as probable cause of myocardial insulin resistance and is recognised as an independent risk factor of cardiovascular disease..$^{(29,30)}$

The insulin resistant state is characterised by impaired signalling via the IRS-I/PI-3-Kinase/PKB/Akt-pathway. Reduced insulin receptorand IRS-I tyrosine phosphorylation ${ }^{(31,32)}$ and IRS-I associated PI-3Kinase activity $^{(31)}$ have been reported in adipocytes while lower $\mathrm{PKB} / \mathrm{Akt}$ activity ${ }^{(14)}$ was found in the rat heart. In animal models of obesity and type 2 diabetes $^{(13)}$ as well as in humans, ${ }^{(33,34)}$ attenuated muscle glucose transport has been documented, coupled to ineffective attenuation of hepatic glucose production. In addition, several studies have drawn negative correlations between GSK-3 activity, glucose uptake and muscle glycogen content. ${ }^{(35,36)}$ Currently, there is no evidence for genetic mutations in either one of 
the two GSK-3 genes associated with the development of type 2 diabetes mellitus ${ }^{(37)}$ but there are studies demonstrating upregulation of expression and higher activity of GSK-3 protein in skeletal muscle of type 2 diabetic patients and in adipose tissues of obese diabetic rodent models. ${ }^{(38,39)}$ In addition, it was shown that inhibition of GSK-3 improves insulin action in skeletal muscle of obese, insulin resistant rodents. ${ }^{(40,41)}$ The potential benefits of GSK-3 inhibition for the treatment of insulin resistance and type 2 diabetes, as demonstrated in different animal models, is elegantly reviewed by Wagman et al. ${ }^{(42)}$ In view of the vast amount of literature on this subject, this review will focus mainly on the cardiovascular effects of GSK-3 inhibition with special reference to insulin resistance.

\section{THE HEART IN OBESITY AND INSULIN}

\section{RESISTANCE}

Studies have suggested that several agents are able to induce myocardial insulin resistance by activation of serine/threonine kinases that phosphorylate IRS-I and inhibit its function. ${ }^{(43)}$ These agents include tumor necrosis factor $\alpha(T N F \alpha),{ }^{(44)}$ free fatty acids, ${ }^{(33)}$ cellular stress, ${ }^{(43)}$ angiotensin $\|^{(45)}$ and hyperinsulinemia. ${ }^{(46)}$ Insulin itself may also stimulate serine kinases that promote phosphorylation of IRS- I. ${ }^{(47)}$ According to Gual et al., the inhibition of IRS-I function may represent the unifying mechanistic link between all factors involved in insulin resistance. GSK-3 protein, in its active state, also has the ability to phosphorylate IRS-I on 2 serine residues (Ser307 and 332). ${ }^{(43)}$ This phosphorylation by GSK3 is associated with downregulation of signalling via IRS- ( ${ }^{(48)}$ and may potentially exacerbate insulin resistance and compromise glucose uptake as it is associated with impaired tyrosine phosphorylation of IRS-I and decreased PI-3-Kinase activation. ${ }^{(49)}$ The importance of this observation is underscored by the work of Rao et al. ${ }^{(50)}$ showing enhanced myocardial glucose uptake when GSK-3 is inhibited in high-fat-fed mice and a correction of diabetes in mice with a genetic deficiency of GSK-3 $\beta .^{(51)}$ The latter study indicated that some of the effects of GSK-3 may also lie in the preservation of beta cell mass, therefore insulin secretory abilities.

These effects of GSK-3 $\beta$ therefore argue for a loop of reactions that, once set in motion, will exacerbate insulin resistance. Thus, insulin resistance causes inhibition of the inhibitory phosphorylation of GSK-3 $\beta$ by PKB/Akt, allowing GSK-3 $\beta$ to phosphorylate IRS-I on serine residues which will further inhibit its activation leading to attenuated glut 4 translocation and glucose uptake. Enhanced activity of GSK-3 $\beta$ will also phosphorylate GS thereby inhibiting glycogen formation with resultant elevation of glucose levels (Figure I).

\section{GSK-3 AND MYOCARDIAL CONTRACTILITY}

The diabetic heart is characterised by reduced contractility independent of vascular disease. One of the role players in the changes in contractile function in diabetes, is the calcium pump (SERCA2) of the sarcoplasmic reticulum. Total SERCA2 expression is decreased in hearts from diabetic mice, ${ }^{(52)}$ while myocardial contractility in diabetic mice can be improved by cardiacspecific over expression of SERCA2. ${ }^{(52,53)}$ It has been reported that GSK-3 $\beta$ protein is a critical regulator of calcium handling in the heart. ${ }^{(54)}$ Using genetically manipulated mice that over express myocardial GSK-3 $\beta$, Michael and co-workers showed that GSK-3 $\beta$ acts directly on the SERCA2 promoter to downregulate its expression, leading to systolic and diastolic dysfunction. ${ }^{(54)}$ In addition, they reported impaired fractional shortening and reduced $+d P / d t$ values measured by echocardiographic methods. Cytosolic calcium was significantly elevated in diastole. This was coupled to lower mRNA levels and lower expression of SERCA2a protein. In addition, the non-specific GSK-3 inhibitor LiCl, completely reversed the inhibition of SERCA2 mRNA expression. To underscore these results, King et al., ${ }^{(55)}$ using the protein phosphatase-I/inhibitor-2 complex to regulate the phosphorylation state of GSK-3, demonstrated increased SERCA2 expression. GSK-3 protein, by regulating SERCA2 expression, if elevated, may therefore be intimately involved in the contractile abnormalities of the diabetic heart.

\section{GSK-3 AND DEVELOPMENT OF CARDIAC} HYPERTROPHY

Diabetes is associated with left ventricular hypertrophy and diastolic dysfunction which may eventually lead to clinical heart 
failure. ${ }^{(56)}$ Pre-clinical abnormalities of cardiac structure and function have been reported in diabetes of short duration ${ }^{(57)}$ while echocardiographic studies pointed out the evidence of left ventricular remodeling and demonstrated the existence of a discreet diabetic cardiomyopathy. ${ }^{(56)}$

Cardiac hypertrophy can be either physiological or pathological. Pathological hypertrophy is associated with activation of neurohumoral pathways (endothelin I, angiotensin II, catecholamines) eventually leading to release of calcium from intracellular stores (mainly the sarcoplasmic reticulum). This, in turn, will activate the calcium dependent phosphatase calcineurin, which regulates changes in gene expression associated with hypertrophy. ${ }^{(58)}$ One of the more prominent transcription factors regulated by calcineurin is nuclear factor of T-cells (NFAT). ${ }^{(59)}$ These authors showed that cardiac hypertrophy is induced by calcineurin, which dephosphorylates NFAT-3, enabling it to translocate to the nucleus. NFAT3 interacts with the cardiac zinc finger transcription factor GATA4, resulting in activation of gene transcription. GSK-3 $\beta$ can counter- act the activity of calcineurin by phosphorylating NFAT. Studies done with models of myocardial overexpression of GSK-3 $\beta$ have shown that GSK-3 $\beta$ is one of the most powerful antihypertrophic entities described thus far. ${ }^{(60,61)}$ Using $\mathrm{LiCl}$, a non-specific inhibitor of GSK-3, Haq et al.(60) demonstrated that inhibition of GSK-3 activity leads to features of cardiac hypertrophy. This observation is underscored by the finding that deletion of GSK-3 $\beta$ in mice resulted in hypertrophic cardiomyopathy. ${ }^{(62)}$ No live GSK-3 $\beta^{-/-}$pups were recovered in this study. The embryos had cardiac developmental defects caused by cardiomyocyte hyperproliferation associated with increased expression and nuclear translocation of 3 regulators of proliferation - GATA4, cyclin DI and c-Myc. It is also interesting to note that many hypertrophic stimuli inhibit GSK-3 $\beta$, thereby removing its negative constraints on the development of hypertrophy.

Besides the abovementioned inactivation of GSK-3 $\beta$ through phosphorylation on Ser9, it can also be inactivated by activation of the Wnt/frizzled pathway (Figure 2). This inactivation is apparently

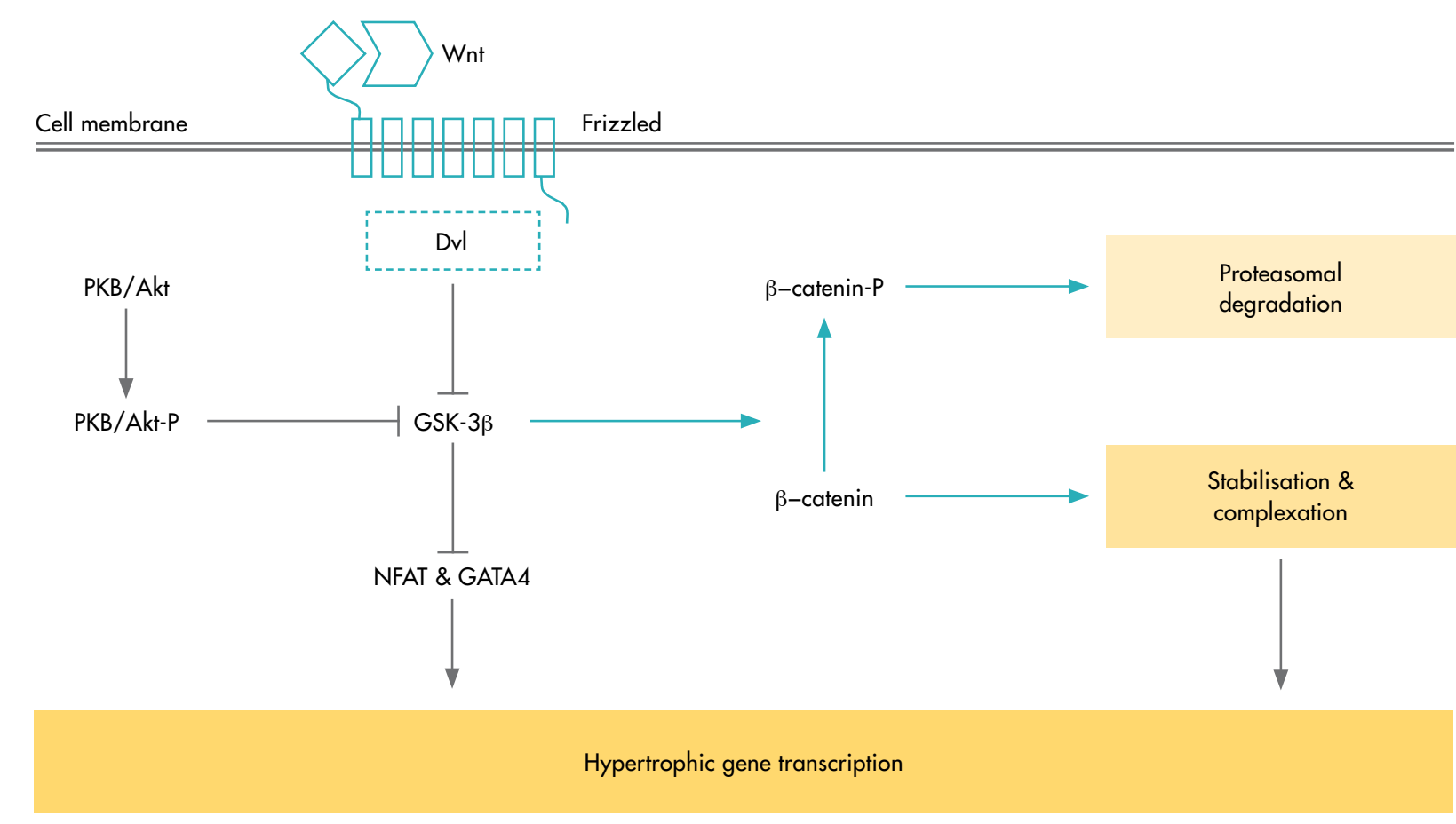

FIGURE 2: A schematic representation of Wnt signalling in the context of GSK-3 involvement.

Wnt: ligand of the frizzled receptor, Dvl: disheveled is an intermediate protein relaying the signal from the receptor to a target protein, GSK-3ß: glycogen synthase kinase-3 beta, NFAT: nuclear factor of activated T-cells, GATA4: transcription factor. 
because of sequestration of the kinase rather than phosphorylation thereof. Blankestein and co-workers ${ }^{(58)}$ reviewed the role of the Wnt/frizzled pathway in the inhibition of GSK-3 $\beta$, arguing for a therapeutic anti-hypertrophic strategy by inhibiting Wnt/ frizzled signalling.

It is generally accepted that there is re-expression of the fetal gene programme in the hypertrophic heart, ${ }^{(63)}$ therefore, according to Blankestein, Wnt/frizzled signalling may be reactivated in the hypertrophic heart. They could show upregulation of frizzled-2 expression in pressure overload hypertrophy in the rat $^{(64)}$ and demonstrated a causal relationship between this expression and the development of hypertrophy. ${ }^{(65)}$

But, as highlighted by the result of Kerkela et al., (62) inhibition of GSK-3 remains a 2-faced Janus. The Wnt glycoproteins are essential for proper embryonic development due to their role in the regulation of cellular proliferation, differentiation, motility and polarity. ${ }^{(66-68)}$ Already in 1995, Klein \& Melton put forward a hypothesis that the effects of lithium on development of diverse organisms, was because of the inhibition of Wnt signalling by GSK$3 \beta{ }^{(69)}$ Wnts act as ligands for the frizzled family of receptors. It elicits a response via the stabilisation of $\beta$-catenin, resulting in accumulation of the latter in the cytosol and nucleus where it results in activation of transcription of Wnt target genes. ${ }^{(66)}$ GSK-3 $\beta$ phosphorylates $\beta$-catenin, targeting it for ubiquitination and proteasomal degradation. ${ }^{(68)}$ Mutations in $\beta$-catenin at the residues that can be phosphorylated by GSK-3 $\beta$ is associated with development of numerous types of cancer. ${ }^{(70)}$

\section{GSK-3 AND MYOCARDIAL CELL DEATH OR CELL SURVIVAL}

It is well-recognised that, clinically, diabetes results in increased mortality and enhanced left ventricular dysfunction following myocardial infarction after ischaemia/reperfusion. ${ }^{(71,72)}$ Recently, Sena et al. ${ }^{(73)}$ used cardiomyocyte-restricted insulin receptor knock out (CIRKO) mice to investigate possible mechanisms responsible for this. In a model of proximal coronary artery ligation to induce infarction, they followed changes in the heart over a 14 day period.
Notably, they demonstrated enhanced left ventricular dysfunction coupled to accelerated mitochondrial dysfunction as well as attenuated expression of several proteins involved in glucose and fatty acid oxidation. In addition, SERCA2 expression was down regulated in the CIRKO mice.

In the context of ischaemic heart disease, the concept of ischaemic and pharmacological preconditioning has been intensively researched in the last decade. Ischaemic preconditioning refers to the phenomena whereby a series of short periods of myocardial ischaemia interspersed with reperfusion, has the ability to protect the heart against a successive longer period of ischaemia. (74) Because ischaemic preconditioning is still the most powerful endogenous protective mechanism that can be elicited in the heart, research centered on elucidating the mechanism thereof with the aim of duplicating it via pharmacological means. This was no easy matter as research demonstrated that different stimuli have the ability to mimic ischaemic preconditioning, leading to the search for a common denominator or end-effector. Since the balance between cell death and cell survival is central to ischaemic damage to the heart, research centered on signalling pathways that influence mitochondrial function and integrity. Some of these pathways implicated in preconditioning, are endogenous ligands released during ischaemia which would activate G-protein coupled receptors (adenosine, bradykinin, isoproterenol or opioids) that, in turn, activated a cascade of protein kinases (e.g. PKB, PKC, PKA, ERK, P38MAPK) that could influence mitochondrial integrity. ${ }^{(75-79)}$ Following on the observation of Tong et al. ${ }^{(80)}$ that preconditioning resulted in phosphorylation and inactivation of GSK-3 $\beta$ via a PI3Kinase mediated pathway, the work of Juhaszova et al. ${ }^{(81)}$ took this one step further and demonstrated that the upstream effector that could integrate all the diverse signalling effects implicated in preconditioning, was GSK-3 $\beta$. Using two of the new-generation GSK-3 inhibitors, Das and colleagues( ${ }^{(82)}$ demonstrated that pretreatment of hearts before ischaemia, with these inhibitors, was as protective as preconditioning. They furthermore confirmed the mitochondria as end-target of this protection. According to their results, GSK inhibition decreased mitochondrial membrane potential with less calcium loading and less oxygen radical production, thereby conferring protection. In addition, mitochondrial 
affinity for the anti-apoptotic protein $\mathrm{Bcl}-2$ increased, with more $\mathrm{BCl}-2$ associated with mitochondria in the presence of GSK-3 inhibition, inferring a pro-apoptotic role for GSK-3. This conclusion is substantiated by the work of Hirotani et al.,(83) using a transgenic mouse with cardiac-specific expression of a dominant negative form of GSK-3 $\beta$, who demonstrated accumulation of the antiapoptotic molecule MCL-I in these animals. This, as well as the anti-apoptotic effects of GSK-3 inhibition, could be abolished by knock down of MCL-I with small inhibitory RNA molecules. All these effects could therefore contribute to the observed cardioprotective effect of the GSK inhibitors. It must be kept in mind that a pro-apoptotic role for GSK-3 would also argue for an inhibition of hypertrophy, as discussed previously.

As mentioned before, there are studies demonstrating upregulation of expression and higher activity (therefore more of the less phosphorylated form) of GSK-3 protein in skeletal muscle of type 2 diabetic patients and in adipose tissues of obese diabetic mice. ${ }^{(38,39)}$ Investigating the protection afforded by post-conditioning (where, in contrast to pre-conditioning, the short, repetitive episodes of ischaemia/reperfusion are implemented immediately at the onset of reperfusion to elicit protection) ${ }^{(84)}$ Wagner et al. (2008) could not elicit post-conditioning in a rat model with metabolic syndrome. ${ }^{(85)}$ This was accompanied by a failure of post-conditioning to result in phosphorylation and inhibition of GSK-3 $\beta$.

On the other hand, Nishino et al., ${ }^{(86)}$ using a mouse line lacking the critical N-terminal serine within myocardial GSK-3 $\beta$ (Ser9) as well as Ser2I in GSK-3 $\beta$, still found protection via preconditioning in the isolated, perfused heart subjected to ischaemia, excluding a role for inhibition of GSK-3 in this phenomenon in the mouse heart as opposed to the findings of Juhaszova in the rat heart. ${ }^{(81)}$

\section{GSK-3 INHIBITION INTHE HEART -}

\section{ATUG-OF-WAR?}

At this stage, it would therefore seem as if the vote on inhibition of GSK-3 as a therapeutic intervention, especially with regards to the heart, is too close to call.
As mentioned, the kinase GSK-3, is involved in not only the regulation of glycogen synthesis and the development of insulin resistance and type 2 diabetes, but is implicated in an array of biological processes including cell death and survival and developmental patterning. It is also associated with the development of various neurodegenerative abnormalities e.g. Alzheimers disease, schizophrenia and possibly Huntington's disease. It is furthermore implicated in the development of different forms of cancer, to name but a few. ${ }^{(87)}$ From this it can be deduced that the inhibition of GSK-3 has a very high therapeutic potential in a number of different human diseases.

As is indicated by the preceding discussion, in the field of cardiology, the list of "positives" of GSK-3 inhibition will probably outweigh that of the "negatives". Inhibition of GSK-3 signalling will inhibit apoptosis, and therefore reduce the damage caused by myocardial ischaemia. It is protective in heart failure. It improves insulin sensitivity not only by enhancing hepatic glycogen synthesis and reducing hepatic glucose output, but also improves whole body glucose tolerance by the enhancement of glut 4 protein levels in the cell membranes of skeletal muscle cells. Inhibition of GSK-3 should improve contractile function in states of insulin resistance via upregulation of SERCA2 expression and it should also have anti-inflammatory effects via inhibition of activation of NF- $\mathrm{KB}^{\left({ }^{(87)}\right.}$ The latter speculation is substantiated by one report showing that the GSK-3 inhibitor TDZD-8, when given to ex vivo perfused rat hearts at the start of reperfusion after ischaemia, presented with reduced NF-KB activation coupled to smaller infarct size and reduced apoptosis. ${ }^{(88)}$ In addition, the work of Sato et al. (2004) demonstrated that a specific inhibitor of GSK-3 has the ability to maintain self-renewal and pluripotency in human and mouse embryonic stem cells. ${ }^{\left({ }^{89}\right)}$ This was probably because of increased $\beta$-catenin activity from activation of the Wnt signalling pathway. Following on this, Tseng et al. (2006) published results to show that inhibition of GSK-3 was also able to raise $\beta$-catenin activity in neonatal rat cardiomyocytes. ${ }^{(90)}$ GSK-3 inhibition in these cells induced cell cycle entry at the S-phase and resulted in cell division. They tested whether this would hold true in adult rat cardiomyocytes and showed that GSK-3 inhibition also induced adult rat and mammalian cardiomyocytes to dedifferentiate and 
undergo mitosis. In the heart, with its lack of proliferative potential and formation of scar tissue after infarction, treatment able to induce proliferation and regeneration, will have enormous potential.

On the down side of inhibition of GSK-3 lies the fact that these inhibitors are mostly non-specific, that their use may lead to development of cardiac hypertrophy because of a lift on the inhibition of calcineurin and furthermore, that GSK-3 inhibition may be teratogenic. In other tissue, inhibition of GSK-3 may induce different forms of cancer e.g. colorectal cancers have defects in elements of the Wnt pathway that lead to accumulation of $\beta$-catenin ${ }^{(91)}$ that will be exacerbated by GSK-3 inhibition. However, available data do not show enhanced incidence of cancer in patients after long-term treatment with lithium. ${ }^{(92)}$ Furthermore, under some circumstances, GSK-3 inhibitors might be useful in treating specific cancers. ${ }^{(93)}$

Currently, more than 30 different GSK-3 inhibitors have been described. ${ }^{(2,94)}$ As summarised by these reviews, they have a diversity of structure and size but most of them are small in order to reach GSK-3 where it is embedded in protein complexes, and most of them act by competing with ATP in the ATP-binding site of the kinase. Unfortunately, even the inhibitors described as more selective, ${ }^{(10)}$ will also inhibit other protein kinases. ${ }^{(94)}$ All of the available GSK-3 inhibitors will lead to elevated $\beta$-catenin levels. ${ }^{(68)}$ Despite this, no deleterious effects have yet been reported in rodent studies. However, it seems that there is an absence of long-term studies with GSK-3 inhibitor treatment in rodent models of disease. Most of the negative effects have been reported using genetically modified animals. At the moment, the bottom line is still that, in the words of Sugden et al. (2008): "we just do not know whether to inhibit or activate GSK-3, or simply not to interfere!" (8)

\section{REFERENCES}

I. Hemmings BA, Yellowlees D, Kernohan JC, et al. Purification of glycogen synthase kinase 3 from rabbit skeletal muscle. Copurification with the activation factor (FA) of the (Mg-ATP) dependent protein phosphatase. Eur J Biochem 1981; | 19:443-45।.

2. Martinez A. Preclinical efficacy on GSK-3 inhibitors: towards a future generation of powerful drugs. Medicinal Research Reviews 2008:28:773-796.

3. Opie LH. Heart Physiology - from cell to circulation, Fourth edition:306. Lippincott Williams \& Wilkins.

4. Brazil DP \& Hemmings BA. Ten years of protein kinase B signalling: a hard Akt to follow. Trends in Biochem Sci 2001;26:657-664.

5. Davey KAB, Garlick PB, Warley A, et al. Immunogold labeling study of the distribution of GLUT-I and GLUT-4 in cardiac tissue following stimulation by insulin or ischaemia. Am J Physiol Heart Circ Physiol 2007;292:H2009-H20l9.

6. Cohen P, Alessi DR, Cross DAE. PDKI, one of the missing links in insulin signal transduction? The Tenth Datta Lecture. FEBS Lett 1997;410:3-10.

7. Parker PJ, Caudwell FB, Cohen P. Glycogen synthase from rabbit skeletal muscle; effect of insulin on the state of phosphorylation of the seven phosphoserine residues in vivo. Eur J Biochem 1983; 130:227-234.

8. Sugden PH, Fuller SJ, Weiss SC, et al. Glycogen synthase kinase 3 (GSK3) in the heart: a point of integration in hypertrophic signalling and a therapeutic target? A critical analysis. British J Pharmacol 2008; I53:SI37-SI53.

9. Mora A, Sakamoto K, McManus EJ, et al. Role of the PDK-I-PKB-GSK-3 pathway in regulating glycogen synthase and glucose uptake in the heart. FEBS Lett 2005;579:3632-3638.

10. Henriksen EJ \& Dokken BB. Role of glycogen synthase kinase-3 in insulin resistance and type 2 diabetes. Current Drug Targets 2006;7: |435-144|.

II. Levine R, Goldstein M, Klein S, et al. The action of insulin on the distribution of galactose in eviscerated nephrectomised dogs. J Biol Chem 1949; 179:985-986.

12. Kim YB, Nkonlina SE, Ciaraldi TP, et al. Normal insulin dependent activation of Akt/protein kinase B, with diminished activation of phosphoinositide 3-kinase, in muscle of type 2 diabetics. J Clin Invest 1999; 104:733-74I.

13. Morisco C, Limbo G, Trimarco B. Insulin resistance and cardiovascular risk: New insights from molecular and cellular biology. Trends Cardiovasc Med 2006;16: 183-188.

14. Huisamen B. Protein kinase B in the diabetic heart. J Mol Cell Biochem 2003: 249:31-38.

15. Kraegen EW, Sowden JA, Halstead MB, et al. Glucose transporters and in vivo glucose uptake in skeletal and cardiac muscle: fasting, insulin stimulation and immuno-isolation studies of Glut I and Glut 4. Biochem 1993;295:287-293.

16. An D \& Rodrigues B. Role of changes in cardiac metabolism in development of diabetic cardiomyopathy. Am J Physiol, Heart and Circ Physiol 2006;291: 1289-1506.

17. Abel, ED. Glucose transport in the heart. Front Bioscience 2004;9:20I-215.

18. Slot JW, Geuze HJ, Gegengack S, et al. Translocation of the glucose transporter Glut 4 in cardiac myocytes of the rat. Proc Natl Acad Sci USA 1991;88: 7815-7819.

19. Reaven GM. The role of insulin resistance in human disease. Diabetes 1988 37:1595-1607.

20. Haffner SM. Obesity and the metabolic syndrome: the San Antonio Heart Study. British J of Nutrition 2000; 83, Suppl I:S67-S70.

21. Grundy SM. Metabolic syndrome: connecting and reconciling cardiovascular and diabetes worlds. J Am Coll Cardiol 2006;47: 1093-1 100.

22. Alexander CM, Landsman PB, Teusch SM, et al. NCEP-defined metabolic syndrome, diabetes and prevalence of coronary hart disease among NHANES III participants age 50 years and older. Diabetes 2003;52:1210-1213. 
23. Balkau B \& Charles MA. Comment on the provisional report from the $\mathrm{WHO}$ Consultation. European Group for the Study of Insulin Resistance (EGIR). Diabet Med 1999; | 6:44|-443.

24. National Cholesterol Education Programme (NCEP) Expert panel on detection, evaluation and treatment of high blood cholesterol in adults. Third report of the NCEP - adult treatment panel III, final report. Circ 2002; 106:3143-342I.

25. Zimmet P, Alberti KG, Shaw J. Global and societal implications of diabetes epidemic. Nature 2001;414:782-787.

26. Mlinar B, Marc J, Janez A, et al. Molecular mechanisms of insulin resistance and associated disease. Clin Chim Acta 2007;375:20-35.

27. Pyörälä K. Hyperinsulinaemia as predictor of atherosclerotic vascular disease, epidemiological evidence. Diabetes Metab 1991;17:87-92.

28. Turner RC, Millns H, Neil HA, et al. Risk factors for coronary artery disease in non-insulin dependent diabetes mellitus: United Kingdom prospective Diabetes Study (UKPDS:23). BMJ 1998;31 6:823-828.

29. Smith SC Jr. Multiple risk factors for cardiovascular disease and diabetes mellitus. Am J Med 2007; |20:S3-SII.

30. Rader DJ. Effect of insulin resistance, dyslipidaemia and intra-abdominal adiposity on the development of cardiovascular disease and diabetes mellitus. Am J med 2007; 120:S12-S18.

31. Paz K, Hemi R, leRoith D, et al. A molecular basis for insulin resistance. Elevated serine/threonine phosphorylation of IRSI and IRS2 inhibits their binding to the juxtamembrane region of the insulin receptor and impairs their ability to undergo insulin-induced tyrosine phosphorylation. J Biol Chem 1997;272:299| I-29918.

32. Tanti J-F, Grémeaux T, Van Obberghen E, et al. Serine/Threonine phosphorylation of insulin receptor substrate I modulates insulin receptor signaling. J Biol chem. 1994;269:6051-6057.

33. Shulman Gl. Cellular mechanisms of insulin resistance. J Clin Invest 2000;106: |7|-176.

34. Mueckler M. Insulin resistance and the disruption of glut 4 trafficking in skeletal muscle. J Clin Invest 2001;107:1211-1213.

35. Derave W, Hansen BF, Lund S, et al. Muscle glycogen content affects insulinstimulated glucose transport and protein kinase B activity. Am J Physiol Endocrinol Metab 2000;279:E947-E955.

36. Ring DB, Johnson KW, Henriksen EJ, et al. Selective glycogen synthase kinase 3 inhibitors potentiate insulin activation of glucose transport and utilisation in vitro and in vivo. Diabetes 2003;52:588-595.

37. Hansen L, Arden KC Rasmussen SB, et al. Chromosomal mapping and mutational analysis of the coding region of the glycogen synthase kinase-3alpha and beta isoforms in patients with NIDDM. Diabetologia 1997;40:940-946.

38. Nikoulina SE, Ciaraldi TP, Mudaliar S, et al. Potential role of glycogen synthase kinase-3 in skeletal muscle insulin resistance of type 2 diabetes. Diabetes 2000;49:263-271.

39. Eldar-Finkelman H,Schreyer SA, Shinohara MM, et al. Increased glycogen synthase kinase-3 activity in diabetes- and obesity-prone C57BL6J mice. Diabetes 1999;48:1662-1666

40. Dokken BB, Sloniger JA, Henriksen EJ. Acute selective glycogen synthase kinase-3 inhibition enhances insulin signaling in prediabetic insulin resistant rat skeletal muscle. Am J Physiol Endocrinol Metal 2005;288:El I88-El 194.

41. Henriksen EJ, Teachey MK. Short-term in vitro inhibition of glycogen synthase kinase 3 potentiates insulin signaling in type I skeletal muscle of Zucker diabetic fatty rats. Metabolism 2007;56:931-938.

42. Wagman AS, Johnson KW, Bussiere DE. Discovery and development of GSK3 inhibitors for the treatment of type 2 diabetes. Curr Pharm Des 2004; 1 0:1 I05II37.
43. Gual P, Le Marchand-Brustel Y, Tanti JF. Positive and negative regulation of insulin signalling through IRS-I phosphorylation. Biochimie 2005;87:99-109.

44. Kanety $H$, Feinstein R, Papa MZ, et al. Tumor necrosis factor alpha induced phosphorylation of insulin receptor substrate-I (IRS-I). Possible mechanism for suppression of insulin stimulated tyrosine phosphorylation of IRS. J Biol Chem 1995;270:23780-23784.

45. Folli F, Kahn CR, Hansen $\mathrm{H}$, et al Angiotensin II inhibits insulin signalling in aortic smooth muscle cells at multiple levels. A potential role of serine phosphorylation in insulin/angiotensin II crosstalk. J Clin Invest 1997;100:2158-2169.

46. Schmitz-Pheiffer $C$ \&Whitehead JP. IRS-I regulation in health and disease. IUBMB Life 2003;55:367-374.

47. Griffin ME, Marcucci MJ, Cline GW, et al. Free fatty acid-induced insulin resistance is associated with activation of protein kinase $C$ theta and alterations in the insulin signalling cascade. Diabetes 1999;48:1270-1274.

48. Eldar-finkelman $\mathrm{H}$ \& Krebs EG. Phosphorylation of insulin receptor substrate I by glycogen synthase kinase 3 impairs insulin action. Proc Natl Acad Sci. USA. 1997 94:9660-9664.

49. Aguirre $\mathrm{V}$, Uchida $T$, Yenush $\mathrm{L}$, et al. The c-Jun NH2-terminal kinase promotes insulin resistance during association with insulin receptor substrate-I and phosphorylation of Ser307. J Biol Chem 2000;275:9047-9054.

50. Rao R, Hao CM, Redha R, et al. Glycogen synthase kinase 3 inhibition improves insulin-stimulated glucose metabolism but not hypertension in high-fat-fed C57BL/6J mice. Diabetologia 2007;50:452-460.

5।. Tanabe K, Liu Z, Patel S, et al. Benetic deficiency of glycogen synthase kinase-3beta corrects diabetes in mouse models of insulin resistance. PLoS Biol 2008;6:e37.

52. Suarez J, Scott B, Dillmann WH. Conditional increase in SERCA2a protein is able to reverse contractile dysfunction and abnormal calcium flux in established diabetic cardiomyopathy. Am J Physiol Regul Integr Comp Physiol 2008;295: RI439-RI445.

53. Trost SU, Belke DD, Bluhm WF, et al. Overexpression of the sarcoplasmic reticulum $\mathrm{Ca}(2+)$-ATPase improves myocardial contractility in diabetic cardiomyopathy. Diabetes 2002;51:1166-1171.

54. Michael A, Haq $S$, Chen $X$ et al. Glycogen synthase-kinase- $3 \beta$ regulates growth, calcium homeostasis and diastolic function in the heart. J Biol Chem 2004 279:21383-21393.

55. King TD, Gandy JC, Bijur GN. The protein phosphatase-1/inhibitor-2 complex differentially regulates GSK3 dephosphorylation and increases sarcoplasmic/ endoplasmic reticulum calcium ATPase 2 levels. Exp Cell Res 2006;312 3693-3700.

56. Galderisi M. Diastolic dysfunction and diabetic cardiomyopathy: evaluation by Doppler echocardiography. J Am Coll Cardiol 2006;48:1548-I55 I.

57. Whalley GA, Gusso S, Hofman P, et al. Structural and functional cardiac abnormalities in adolescent girls with poorly-controlled type 2 diabetes mellitus. Diabetes Care 2009; Epub ahead of print.

58. Blankesteijn WM, Van de Schans VAM, Ter Horst P, et al. The Wnt/frizzled/ GSK-3 $\beta$ pathway; a novel therapeutic target for cardiac hypertrophy. Trends in Pharmacological Sciences 2008;29:175-180.

59. Molkentin JD, Lu J-R, Antos CL, et al. A calcineurin-dependent transcriptional pathway for cardiac hypertrophy. Cell 1998;93:215-228.

60. Haq S, Choukroun G, Ranu $H$, et al. Glycogen synthase kinase- $3 \beta$ is a negative regulator of cardiomyocyte hypertrophy. J Cell Biol 2000;151:1 17-129.

61. Antos CL, McKinsey TA, Frey N, et al. Activated glycogen synthase- $3 \beta$ suppresses cardiac hypertrophy in vivo. Proc Natl Acad Sci USA 2002;99:907-912. 
62. Kerkela R, Kockeritz L, Kacaulay K, et al. Deletion of GSK-3beta in mice leads to hypertrophic cardiomyopathy secondary to cardiomyoblast hyperproliferation. J Clin Invest 2008; I 18:3609-3618.

63. McMullen JR \& Jennings GL. Differences between pathological and physiological cardiac hypertrophy: novel therapeutic strategies to treat heart failure. Clin Exp Pharmacol Physiol 2007;34:255-262.

64. Blankesteijn WM, Essers-Janssen YP, Ulrich MM, et al. Increased expression of a homologue of Drosophila tissue polarity gene 'frizzled' in left ventricular hypertrophy in the rat, as determined by subtractive hybridization. J Mol Cell Cardiol 1996;28:1 |87-1191.

65. Van de Schans VA, Van den Borne SW, Strelecka AE, et al. Interruption of Wnt signaling attenuates the onset of pressure overload-induced cardiac hypertrophy. Hypertension 2007:49:473-489.

66. Miller JR. The Wnts. Genome Biol 2002;3:REVIEWS300 I.

67. Brade T, Männer J, Kühl M.The role of Wnt signalling in cardiac development and tissue remodeling in the mature heart. Cardiovasc Res 2006;72:198-209.

68. Patel S, Doble B, Woodgett JR. Glycogen synthase kinase-3 in insulin and Wnt signalling: a double-edged sword? Biochem Soc Trans 2004;32:803-808.

69. Klein PS \& Melton DA. A molecular mechanism for the effect of lithium on development. Proc natl Acad Sci USA 1996;93:8455-8459.

70. Giles RH, van Es JH, Clevers H. Caught up in a Wnt storm: Wnt signaling in cancer. Biochim Biophys Acta 2003; 1 653: I-24.

7I. Haffner SM, Lehto S, Ronnemaa T, et al. Mortality from coronary heart disease in subjects with type 2 diabetes and in nondiabetic subjects with and without prior myocardial infarction. N Engl J Med 1998;339:229-234.

72. Huxley R, Barzl F, Woodward M. Excess risk of fatal coronary heart disease associated with diabetes in men and women: meta-analysis of 37 prospective cohort studies. BMJ 2006:332:73-78.

73. Sena S, Ping $H$, Zhang $D$, et al. Impaired insulin signaling accelerates cardiac mitochondrial dysfunction after myocardial infarction. J Mol Cell Cardiol 2009; Epub doi: 10.1016/j.yjmcc/2009.02.04

74. Murry CE, Jennings RB, Reimer KA. Preconditioning with ischaemia: a delay of lethal cell injury in ischaemic myocardium. Circulation 1986;74:1 | 24- I I36.

75. Gross, G]. The role of mitochondrial KATP channels in cardioprotection. Basic Res Cardiol 2000;95:280-284.

76. Hunter DR \& Hayworth RA. The Ca2+-induced membrane transition in mitochondria. I. The protective mechanisms. Arch Biochem Biophys 1979;195: 453-459.

77. Green DR \& Reed JC. Mitochondria and apoptosis. Science 1998;281: 1309-1312.

78. Javadov SA, Clarke S, Das M, et al. Ischaemic preconditioning inhibits opening of mitochondrial permeability transition pores in the reperfused rat heart. J Physiol 2003;549:513-524.

79. Hausenloy DJ, Maddock HL, Baxter GF, et al. Inhibiting mitochondrial permeability transition pore opening: a new paradigm for myocardial preconditioning? Cardiovasc Res 2002;55:534-543.

80. Tong $\mathrm{H}$, Imahashi K, Steenbergen $\mathrm{C}$, et al. Phosphorylation of glycogen synthase kinase-3beta during preconditioning through a phosphatidylinositol-3-kinasedependent pathway is cardioprotective. Circ Res 2002;90:377-379.

8I. Juhaszova M, Zorov DB, Kim S-H, et al. Glycogen synthase kinase- $3 \beta$ mediates convergence of protection signaling to inhibit the mitochondrial permeability transition pore. J Clin Invest 2004; I 13:1535-1548.

82. Das $\mathrm{S}$, Wong R, Rajapakse N, et al. Glycogen synthase kinase 3 inhibition slows mitochondrial adenine nucleotide transport and regulates voltage-dependent anion channel phosphorylation. Circ Res 2008;103:1-9.
83. Hirotani S, Zhai P,Tomita $\mathrm{H}$, et al, Inhibition of glycogen synthase kinase $3 \beta$ during heart failure is protective. Circ Res 2007; 10 I: I I640 I 174.

84. Vinten-Johansen J, Zhao Z-Q, Zatta AJ, et al. Postconditioning: A new link in nature's amour against myocardial ischaemia-reperfusion injury. Basic Res Cardiol 2005; 100:295-310.

85. Wagner C, Kloeting I, Strasser RH, et al. Cardioprotection by postconditioning is lost in WOKW rats with metabolic syndrome: role of glycogen synthase kinase 3 beta. Cardiovasc Pharmacol 2008;52:430-437.

86. Nishino Y, Webb IG Davidson SM, et al. Glycogen synthase kinase-3 inactivation is not required for ischaemic preconditioning or postconditioning in the mouse. Circ Res 2008; 103:307-314.

87. Martinez A, Castro A, Dorronsoro I, et al. Glycogen synthase kinase 3 (GSK-3) inhibitors as new promising drugs for diabetes, neurodegeneration, cancer and inflammation. Med Res Rev 2002;22:373-384.

88. Gao H-K, Yin Z, Zhou N, et al. Glycogen synthase kinase 3 inhibition protects the heart from acute ischaemia-reperfusion injury via inhibition of inflammation and apoptosis.

89. Sato N, Meijer L, Skaltsounis L, et al. Maintenance of pluripotency in human and mouse embryonic stem cells through activation of Wnt signaling by a pharmacological GSK-3-specific inhibitor. Nat Med 2004; 10:55-63.

90. Tseng A-S, Engel FB, Keating MT. The GSK-3 inhibitor BIO promotes proliferation in mammalian cardiomyocytes. Chemistry \& Biology 2006; 1 3:957-963.

91. Lustig B \& Behrens J. The Wnt signalling pathway and its role in tumor development. J Cancer Res Clin Oncol 2003; 129:199-221.

92. Cohen $Y$, Chetrit A, Cohen $Y$, et al. Cancer morbidity in psychiatric patients: influence of lithium carbonate treatment. Med Oncol 1998; 15:32-36.

93. Liao $X$, Zhang $L$, Thrasher JB, et al. Glycogen synthase kinase-3 $\beta$ suppression eliminates tumor necrosis factor-related apoptosis-inducing ligand resistance in prostate cancer. Mol CancerTher 2003;2:1215-1222.

94. Meijer L, Flajolet M, Greengard P. Pharmacological inhibitors of glycogen synthase kinase 3. Trends in Phar Sci 2004;25:47I-480. 